\title{
Assessment of Virtual Physics Lab (VPL) in summer course for pre-college preparation.
}

\author{
Mr. Varun Kumar Karingula, Indiana University Purdue University, Indianapolis \\ Graduate student from Purdue school of engineering.
}

\section{Dr. Hazim A El-Mounayri, Indiana University Purdue University, Indianapolis}

Dr. El-Mounayri received his PhD in 1997 from McMaster University (in Canada) in Mechanical Engineering, He is currently an associate professor of Mechanical Engineering, the co-director of the Advanced Engineering and Manufacturing Laboratory (AEML) at IUPUI, and a senior scientist for manufacturing applications at Advanced Science and Automation Corp. He co-developed the Advanced Virtual Manufacturing Laboratory for Training, Education and Research (AVML), an innovative e-learning tool for educating students and training the next generation workforce in sophisticated technology and its underlying theory. Dr. El-Mounayri's research focus is in advanced manufacturing, including nano- machining modeling using techniques such molecular dynamics and multiscale simulations, and realization using AFM. Dr. El-Mounayri has worked as consultant for and conducted R\&D for a number of local companies in the areas of CAD/CAM, CNC machining, and process development/improvement. Dr. El-Mounayri is a member of ASME, ASEE, and SME. He has published over 60 technical papers in renowned peer-reviewed journals and technical conferences in his field and gave presentations at various national and international conferences.

\section{Dr. Tamer M. Wasfy, Indiana University Purdue University, Indianapolis \\ Mr. Hatem M Wasfy, Advanced Science and Automation Corp.}

Mr. Hatem Wasfy is the president of Advanced Science and Automation Corp. (ASA) a company that specializes in the development of online virtual learning environments, and advanced engineering simulations. He has helped design several interactive learning environments that include a CNC machining course, a centrifugal pump maintenance course, an undergraduate physics course, and a welding course. He received a B.S. (1994) and an M.S. (1996) in mechanical engineering from the American University in Cairo. Mr. Wasfy's research interests include advanced learning systems, cavitation modeling, computational fluid dynamics, internal combustion engine modeling and design, and AI rule-based expert systems.

\section{Ms. Jeanne Michele Peters, Advanced Science and Automation Corp.}




\title{
Assessment of Virtual Physics Lab (VPL) in summer course for pre-college preparation
}

\begin{abstract}
An innovative virtual physics lab (VPL) which was reported in a previous publication is applied and assessed in the current work. The VPL uses high end multi-media and realistic virtual reality environment to provide an integrated platform for highly effective learning of Physics. Features include fully automated content delivery using text-to-speech technology, highly visual course presentation using animated 2D and 3D illustrations of lectures, interactive 3D experiments, and virtual physics instructor for teaching, training and assistance. Also, the VPL provides game like navigation which is very appealing to the new generation of students, so that they can learn basic physics concepts in more engaging and "fun" way. In this work, the tool is used to support the Upward Bound program at IUPUI. Upward Bound is a federally funded TRIO educational program within the United States, which serves high school students from low-income families and from families in which neither parent holds a bachelor's degree. One of the summer courses offered to those students is Physics. Traditionally, the course was offered without a lab and students had difficulty understanding the concepts. To address this issue, the VPL was used and integrated into the course in a unique and innovative way. In fact, lecture concepts were linked to virtual lab experiment, and each live lecture was followed by a virtual lab session. Students were given pre- and post- test as part of the virtual lab session. Data is collected and analyzed to assess the effectiveness of the VPL. In general, a consistent improvement due to the training and practice in the virtual lab is observed. The VPL presents itself as a viable tool for high school students to better prepare for college physics in cost-effective, easily accessible, and effective way.
\end{abstract}

\section{Introduction}

Having grown with different kinds of digital technology, today's student is aware of most technologies; as a result, he/she is being referred to as the 'Digital student' or part of the 'Net Generation, 1, 2. Information technology has brought unique capabilities to learning spaces, whether stimulating greater interaction through the use of collaborative tools, videoconferencing with international experts, opening virtual worlds for exploration ${ }^{3}$. 
Many results of research on mind games as proved that playing few kind of games greatly improves spatial visualization abilities. There is a number of other useful video games with which children have a chance to increase their abilities including has multitasking and memory. They appear to prefer learning by doing, rather than learning bylistening and often chooses study in group ${ }^{4}$. Therefore, today's student, who have grown up with digital technology will not be completely satisfied with traditional way of teaching involving classroom, teacher, textbooks and blackboard. As the technology is widely growing all around the globe and is more affordable than before, educational institutions are introducing new way of teaching such as video and audio tapes, email, video conferencing, online applications over the internet, etc. The virtual lab environment introduced here creates a new learning experience by integrating thinking, social interaction and technology for the students. The interest in online course is steadily increasing worldwide. According to the recent studies in United States, about one third of higher education students are getting enrolled in at least one online course every year. There is a huge growth in online courses in the last 10 years the compound annual growth rate for online enrollment from fall 2002 to fall 2010 was $18.3 \%{ }^{5}$.

Many educational institutions have adopted these online courses to control the expenditure that are associated with traditional classroom lectures which includes teacher time, class room , educational equipment and supplies, etc. This indicates that in coming future, online education

will become a more dominant form by which students receive instructions in higher learning institutions. Many students are adapted to playing electronic and computer games. Educational researchers found that these kinds of games are educational, and engages students to learn new concepts. These characteristics of games are very helpful in enhancing the thinking, problem solving and overall learning process.

\section{Automation in Online Learning}

Generally the courses can be classified based on how much course content can be accessed online: 1) web facilitated courses where up to $29 \%$ is delivered online; 2) blended courses where up to $79 \%$ of the content is delivered online; and 3) online courses where more than $80 \%$ of the content can be accessed on the internet ${ }^{\mathbf{6}}$. Further the online courses are classified based on the level of automation of the content delivery, which is inversely proportional to the level of involvement of a human instructor ${ }^{7}$. According to the reference level of automation inside the course can be adjusted, in some partially automated course 0 to $29 \%$ of the content of instructor delivered online courses is automated .The instructor in this case will give lectures, responds to student questions, grades assignments and exam. There are some more partially automated courses, where 30 to $79 \%$ of the content is automated. These kind of automated courses include lectures and grading assignments and exams. Fully automated online course have up to $100 \%$ content automation with little or no human instructor involvement in learning process. 
For a student who is taking about 10 classes per year , the average cost per class for tuition fees, books and supplies at 2-year college is approxmently $\$ 400$, while that at a university is around $\$ 900^{\mathbf{8}}$. The estimated cost of a fully automated online course is between $\$ 50$ and $\$ 100$. This represents about $12 \%$ to $25 \%$ of the cost of the cheaper college option. We can notice the annual expenditure of students spending on his education will decrease, without reducing the quality of education. A study of a fully automated high school machining course as suggested that student comprehension, using a well-designed fully automated online course is as effective as traditional classroom/textbook/lab instructions ${ }^{\mathbf{9}}$. Since it is more expensive and time consuming to develop $3 \mathrm{~d}$ graphics as opposed to 2D graphics, course designers should not use 3D graphics indiscriminately for its novelty value. Rather course designer should use 3D graphics when it is necessary. For example, in lab training application on various machines, more effective, realistic training can be performed using 3D virtual reality model of an actual machine ${ }^{\mathbf{1 0}}$.

\section{Virtual Physics Lab}

Achieving a sense of immersion by the students and interactive collaboration among them are two main goals being pursued while developing this new type of educational laboratory at Indiana University Purdue University Indianapolis (IUPUI). This virtual lab on physics, will be introduced to freshman students starting from fall 2013 semester. The course, which is called Virtual Physics Lab or VPL, uses text-to-speech technology to deliver its content in sync with 2D and 3D animation and interactive simulations. All the basic concepts of physics are covered through experiments, some of which are game based. So, it is both "fun" and educational. This approach offers clear advantages over traditional class room lectures, field training or training manuals.

1 - Learners can choose the time they want to learn. In this virtual physics lab, a student can have access anytime through networked computer. In classroom based training, an entire group of students has to attend classes in specific time in regular intervals. If student misses the class for any reason, it will be very difficult for him/her to cover the concept which was covered in the class on that day.

2 - Learners can learn at their own optimum pace. Students using this virtual physics lab gets the chance to learn the concepts clearly, students can adjust the speed at which instructions is presented; he/she can go over the instructions as many times, he can also get a very detailed explanation about the concepts inside this virtual physics lab. 


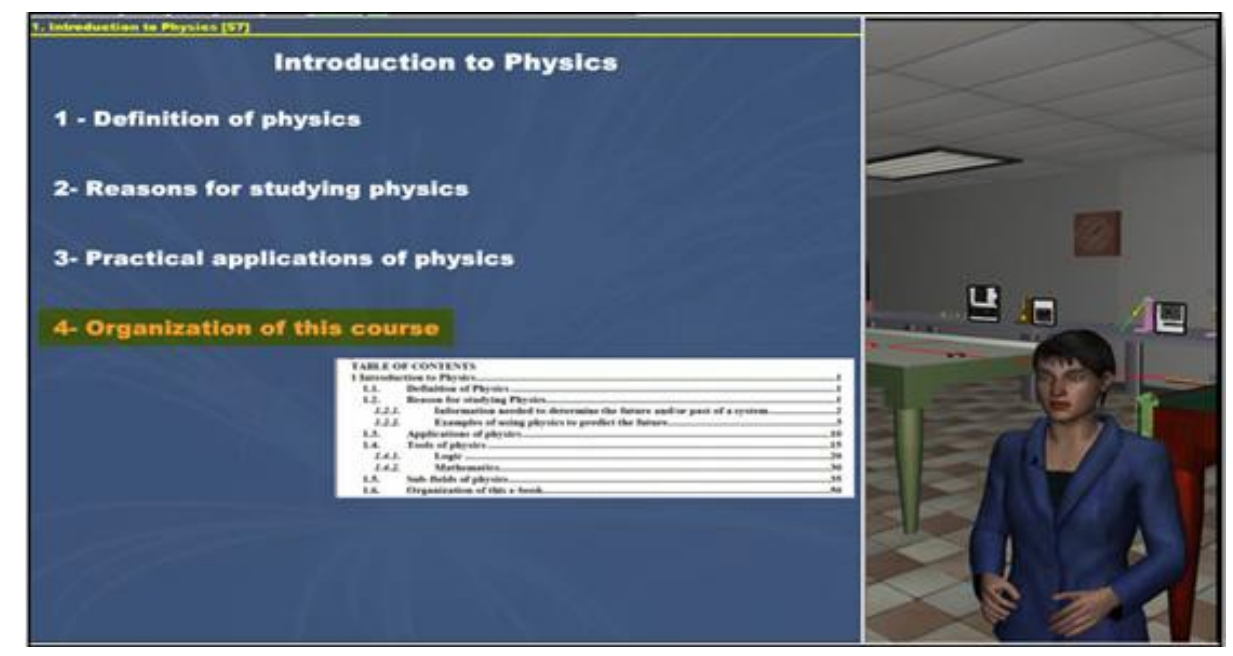

Figure 1: Virtual Physics Lab home screen

3- Multimedia highly interactive and engaging Training Environment. Many educational researchers have found that visual representation is more effective. The virtual physics lab was designed with superior visual representation and interactivity. When the student starts using the virtual physics lab, he/she will be always engaged in learning process.

4 - The ability to learn and experiment within an inherently safe environment. Students can learn the lab experiments in safe environment. Students can have the experience of real time lab, while performing the experiments in virtual physics lab. In future, by the time they are ready to do real time experiments, they will be aware of all the safety factors in that particular environment.

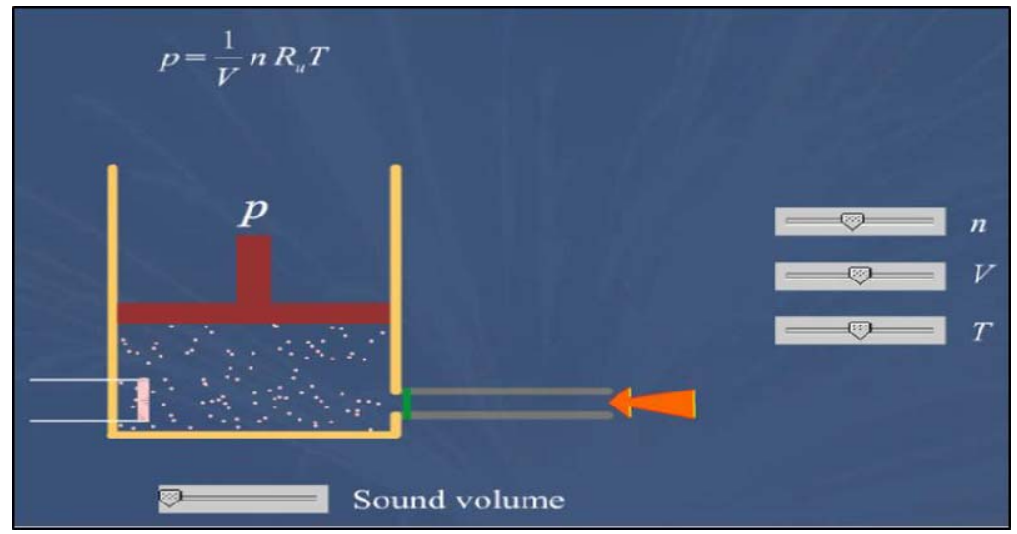

Figure 2: A 2D simulation of the ideal gas law

5 - Minimizing training cost. Virtual physics lab is fully automated, no additional human trainer is required for teaching experiments. Institutions can save their money, which they spend on lab trainers. 
6 - Easy course management. Online web based course management allows course administrator (professor), to check performance of any student and can easily generate the reports and statistics related to course usage.

\section{Upward Bound Program}

Upward Bound is federally funded TRIO education program, which provides fundamental support to participants in their preparation for college entrance. It was designed with the goal to motivate students to enroll in and graduate from a post-secondary institute. Since its launch in 1965, Upward Bound program has been serving high school students from low income families and high school students from families in which neither parents hold a bachelor's degree. Students who participate in Upward Bound Program, are given an opportunity to succeed in their precollege performance and ultimately in their higher education pursuits. The program also aid students and families in the college admissions process ${ }^{\mathbf{1 1}}$.

Indian University- Purdue University Indianapolis (IUPUI), as part of its educational services, conducts Upward Bound program on its campus every summer. IUPUI's Upward Bound program selects students, who are low income, potential first generation college students. Students who attend the Upward Bound program are expected to have a minimum GPA of 2.5. IUPUI provides full scholarship for the high school graduates, who meet the eligibility requirements.

In this prestigious program, the first author was hired as a physics Instructor for summer 2012. There were twelve energetic participants, who took physics with real interest. The audience was multi-cultural, but the majority of the students were from low income African-American families. Out of twelve students, two took physics course in their high school.

\section{General Course Description}

Physics is a very important subject for science and engineering students to succeed in their fields of studies. In this course, a variety of topics is discussed to give a broad prospective of the fundamental of physics. The course consists of lectures, weekly graded homework, several small scale projects, weekly quizzes and a series of laboratory exercises. Homework, quizzes, small scale projects are carried out individually, while lab exercises are conducted in teams. Also, the course involves a midterm exam and a Final exam. 


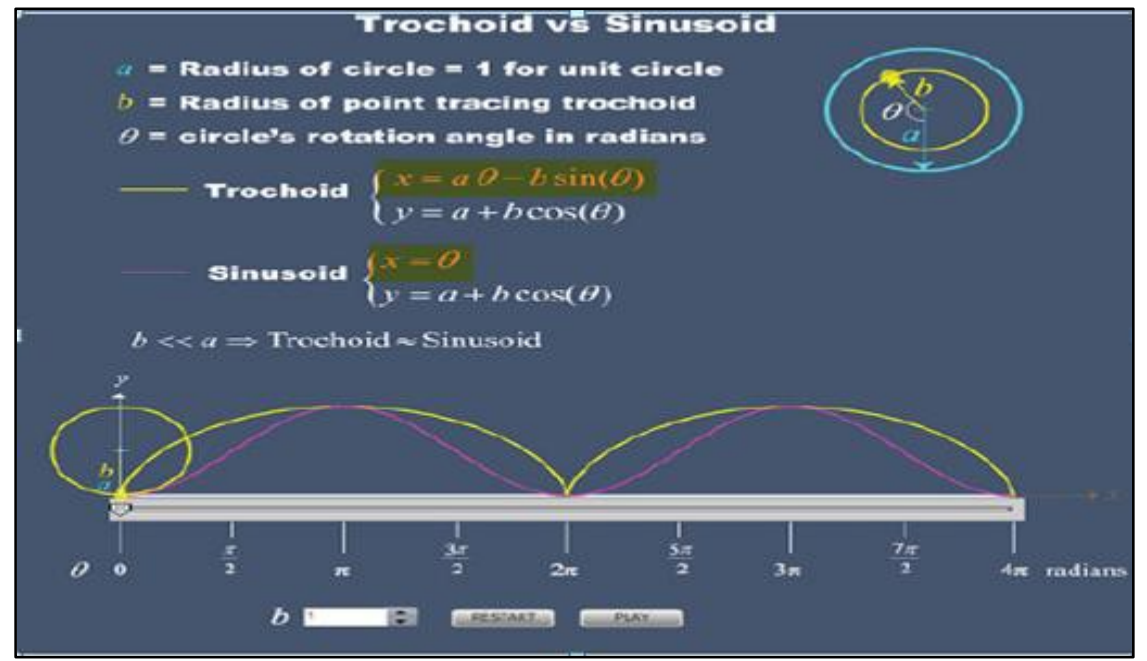

Figure 3 : Explanation of concept in Virtual Physics Lab

Course topics include the following.

1 - Introduction to physics: This chapter mainly concentrates on the basic concepts of physics such as definitions, units, measuring tools etc.

2 - Motions in 1 \& 2 Dimensions: Students are exposed to different motions which act in 1D and

2D.

3 - Forces in 1\&2 Dimensions: This chapter deals with the different forces in nature acting on a body.

4 - Kinematics: Kinematics is a branch of physics that describes the motion of points, bodies (objects) and systems of bodies (groups of objects) without consideration of the causes of motion.

5 - Introduction to Dynamics: It is a branch of physics, which deals with the particles which are in motion.

\section{Procedure}

The course was designed in a way to allow students time to understand the concepts without confusion. Classes, each 45 minutes, were from Monday to Thursday in the mornings. During this time, students are exposed mostly to the theory part of the subject. By the end of the class students were given handouts regarding the experiment which they are supposed to do in the afternoon. 


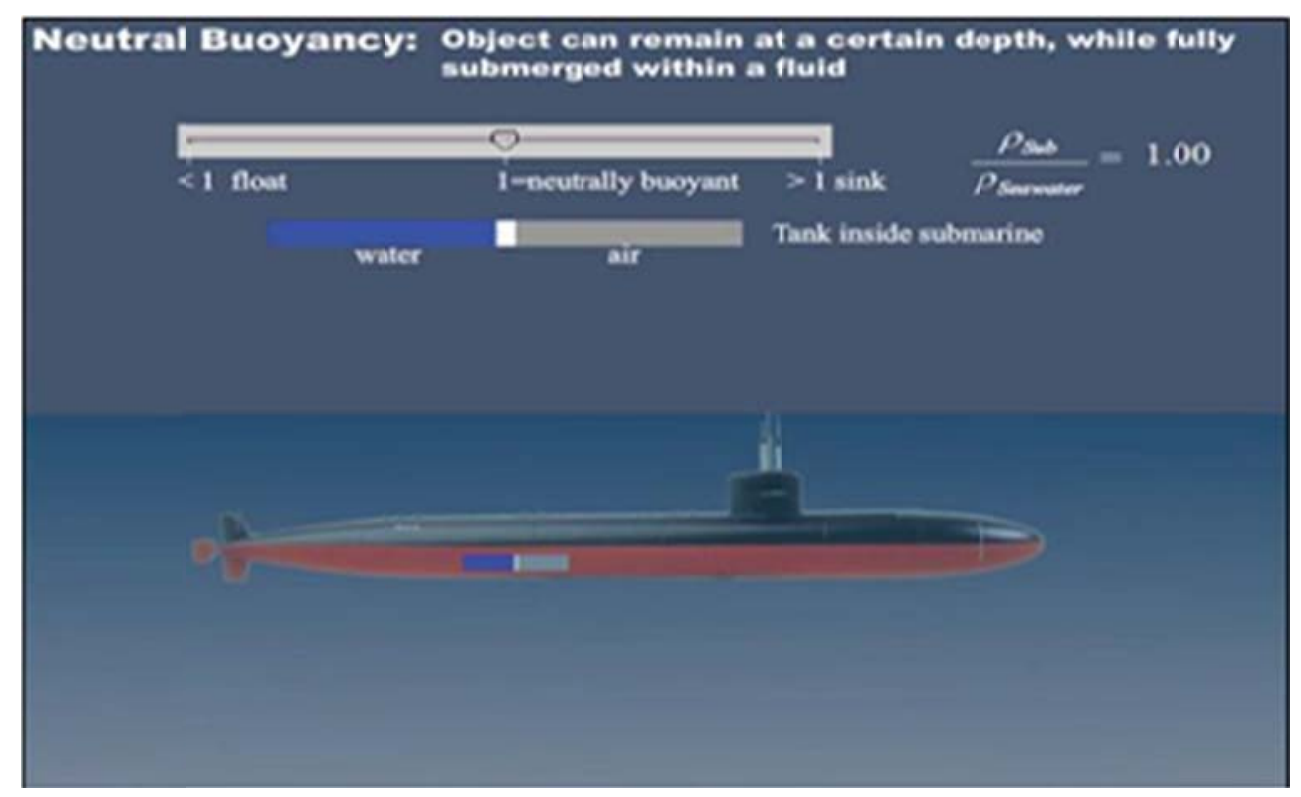

Figure4:Explanation of concept in physics with example in Virtual Physics Lab.

At the beginning the lab, each student completes a Pre-test before starting the experiment. This is to test the students understanding of the concept. The time period for the pre-test is 20 minutes. On the average they have 2 minutes for each question. Following the Pre-test, students complete the experiment in the virtual physics lab. Experimental setup and the way to do the experiment are guided by virtual instructor, which is inside virtual physics lab. The time period for doing the experiment in the lab is allotted as 50 minutes. Group discussions are allowed while doing the experiment in the virtual physics lab, but the experiment in the end has to be performed individually. Group discussions are encouraged because they stimulate innovative thinking. After completing the experiment, a post test is conducted on the same topic. The time period for conducting the post test is 20 minutes. On an average, students have 2 minutes for solving each question.

The level of difficulty of the pre-test is comparable to that of the post-test. The questions are almost identical but not similar. This way we can know how much students have learned from practicing in the virtual lab.

\section{Pre-Experiment test}

The pre-experiment test is conducted before performing the virtual experiments. The main purpose of conducting this test is to assess the student's theoretical knowledge, i.e. understanding of certain concept(s). With such a baseline, we can measure the effect of running the virtual experiments on the level of understanding of the concept(s) by the student. Also, by identifying areas of struggle, remedial actions can be taken. This pre-experiment test was conducted in multiple choice format because of ease of administering and analysis. For each different experimental setup, there was a pre-test conducted. The results of the pre-test indicated that on the average students got $60 \%$ correct answers. 


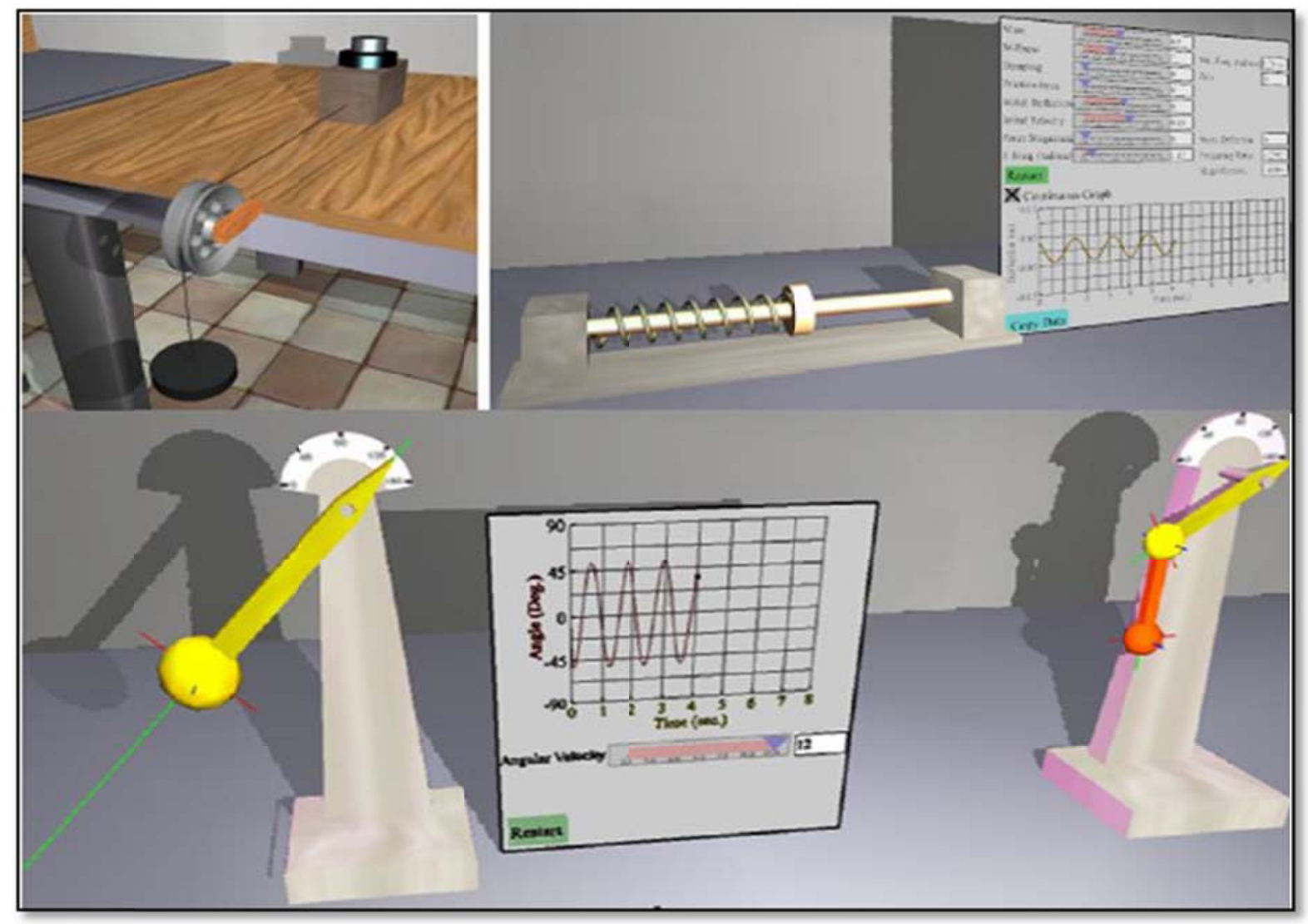

Figure 5: Examples of interactive 3D simulations: block on a flat plane (system top left), mass spring (top right), pendulums (bottom).

\section{Virtual reality based Experimental Setup}

After completing the pre-test on the topic, the students were directed towards the virtual physics laboratory space for physics experiments. Each student had laboratory instructions available on their virtual lab menu. These lab instructions were given by the lab instructor which is inside the virtual physics lab. The virtual Physics lab contains numerous interactive experiments including spring mass system, sliding block on a flat plane, gravity drop, sliding/rolling shapes on an inclined plane, 2-masss pulley, pendulums, sliding and impact on flat surface, and vibration modes of string. Students were directed to listen to the lecture which was given by the lab instructor, in addition to the handouts describing the experiments.

The virtual physics lab can be accessed from anywhere through internet. It provides a lab environment to students were they can perform interactive experiments, some of which are in the form of games. For students that needed additional help, a virtual instructor was available to help them during the running of the experiment. Students can transfer their experimental data from the virtual physics lab to excel sheet by selecting the option called 'copy'; this option provides an easy way for the student to leverage the functionality of excel and perform a rich analysis of the final result. 


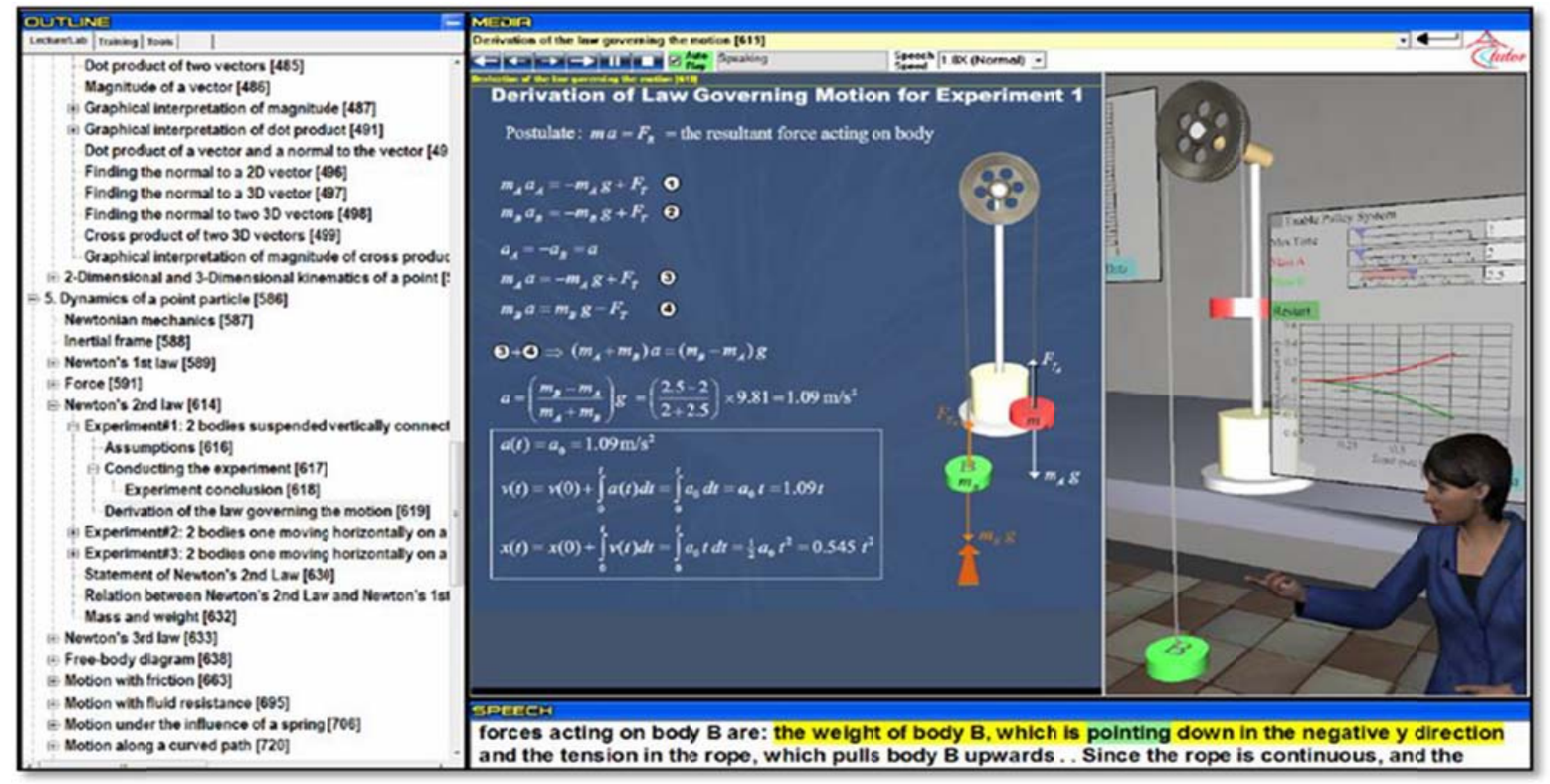

Figure 6: Explanation of experiment by auto instructor in Virtual Physics Lab

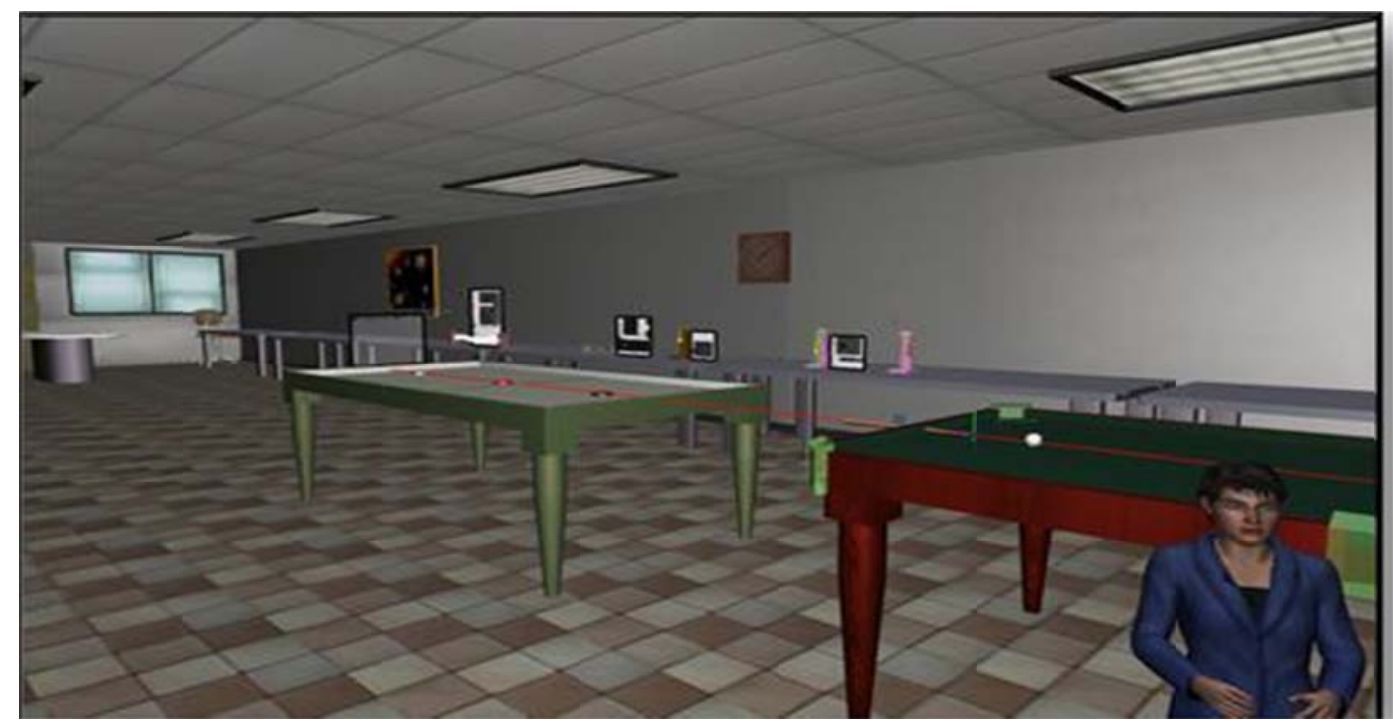

Figure 7: Virtual Environment inside the Virtual Physics Lab

In total, there were four different experiments designed, each related to certain concepts covered in the lecture. Most of them were designed to calculate force, acceleration, etc. by changing several parameters such as mass, angle of inclination etc. This whole thing of doing experiment in virtual environment is expected to help student better understand the concepts. 

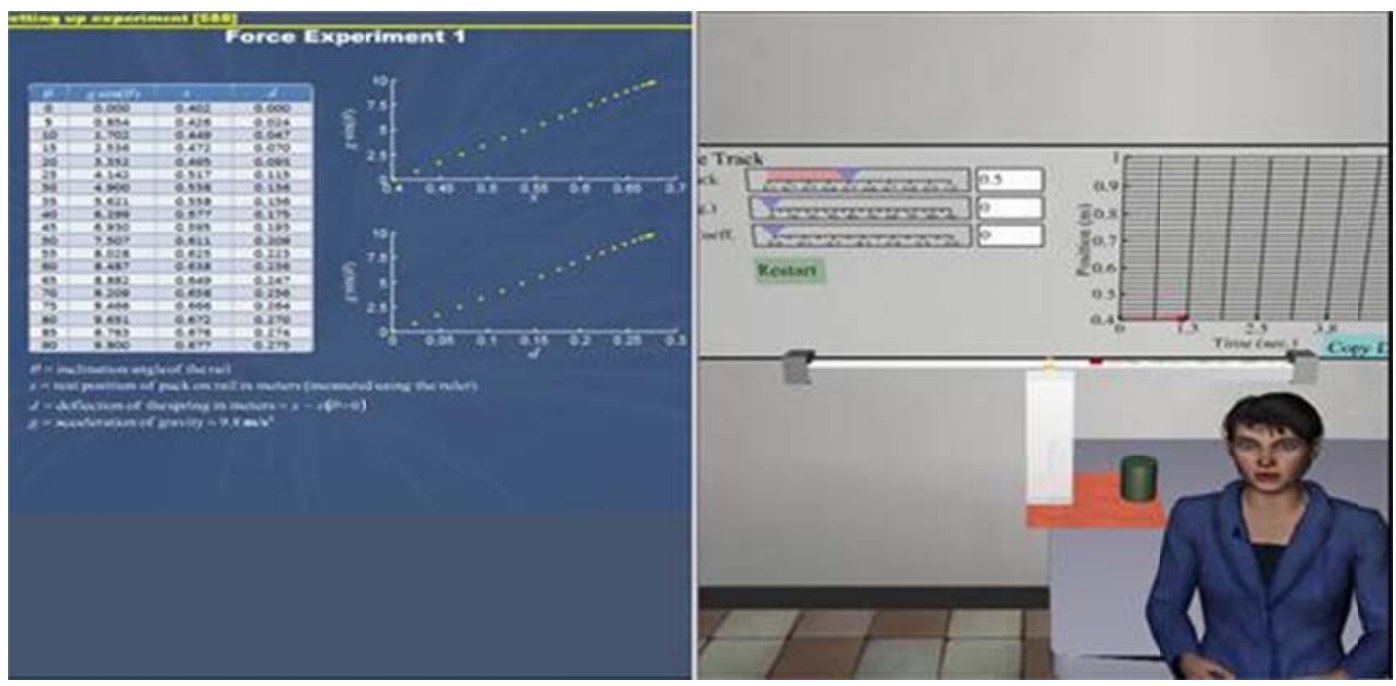

Figure 8: Explanation of force related experiment inside Virtual Physics Lab

\section{Post-Test}

After completing the experimental procedure, the students were given a post-test to assess the learning effectiveness of virtual experiment. The post-test was conducted to measure the improvement of the students in their conceptual knowledge after completing their laboratory exercises. The questions in the post test were not identical but similar to the pre-test ones. The level of difficulty was almost the same. The main reason for not giving the same questions in pre-test and post-test was to eliminate the effect of short term memorization of answers. It was observed that students were more comfortable completing the post-test; they exhibited more confidence, showed better understanding of the concepts (as evidenced by the final scores), and more importantly appeared to "enjoy" writing the post test.

Student's averages in the post test increased, when compared to those in the pre-test. The results of the post test showed that the students answered on an average $75-80 \%$ of the ten questions correctly.

\section{Assessment}

The purpose of the assessment was to determine whether the virtual physics lab had helped the students improve their understanding and knowledge of the concepts taught in the lecture. Also, we wanted to find out whether or not the students had improved in the areas where they showed difficulties during the pre-test. In total, there were twelve students in the class, who attended four lab sessions and completed four experiments in lab. Each student completed a pre-test and post-test for each experiments. The results are shown below (Figures 9 to 16). 


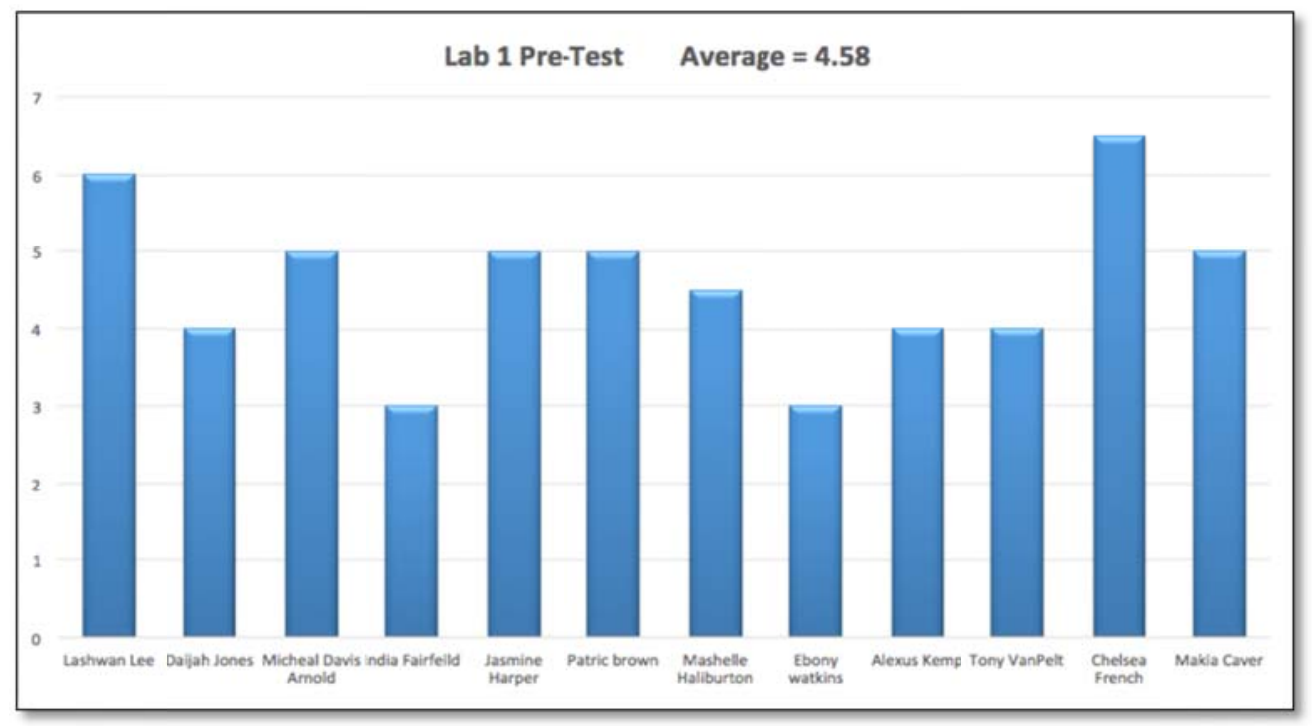

Figure 9: Results of Lab1, Pre-test

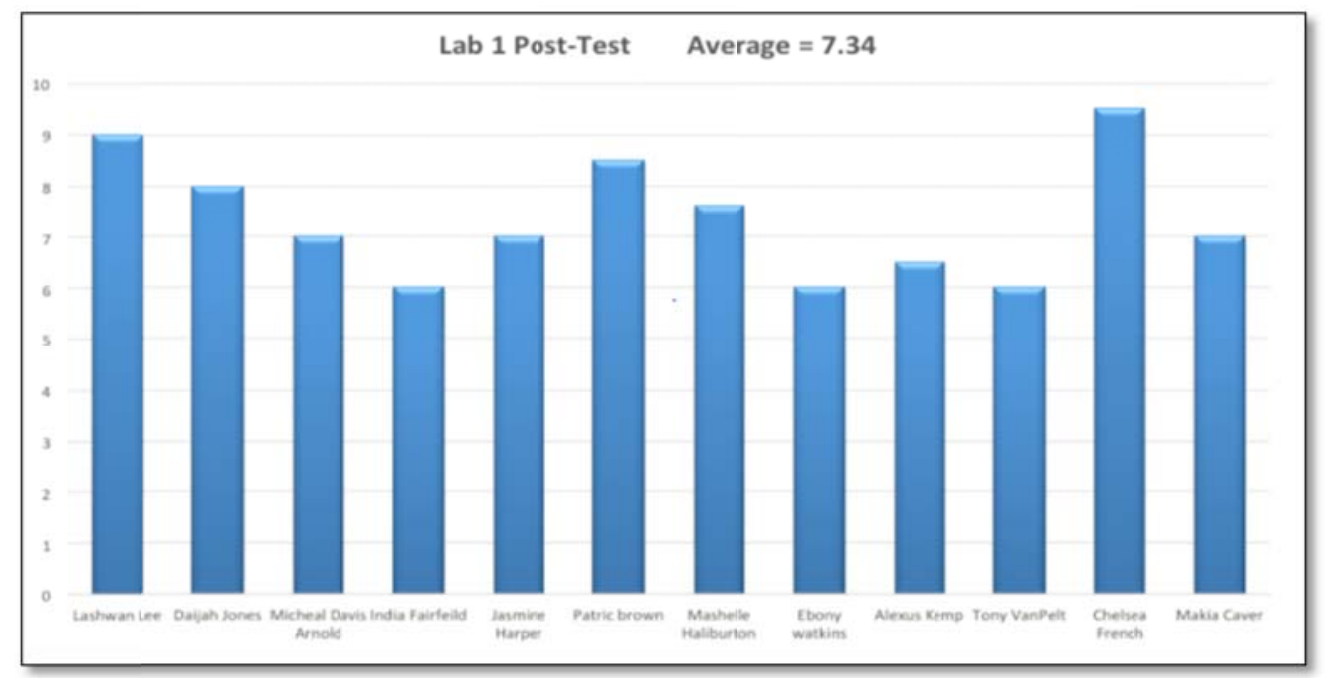

Figure 10: Results of Lab 1, Post-Test

For first experiment, the analysis of pre-test results (Fig. 9) revealed that, on the average, only $45 \%$ of the given ten questions were answered correctly. On the other hand, the results of the post-tests (Fig. 10) show that the students on average answered $74 \%$ of the questions correctly. 


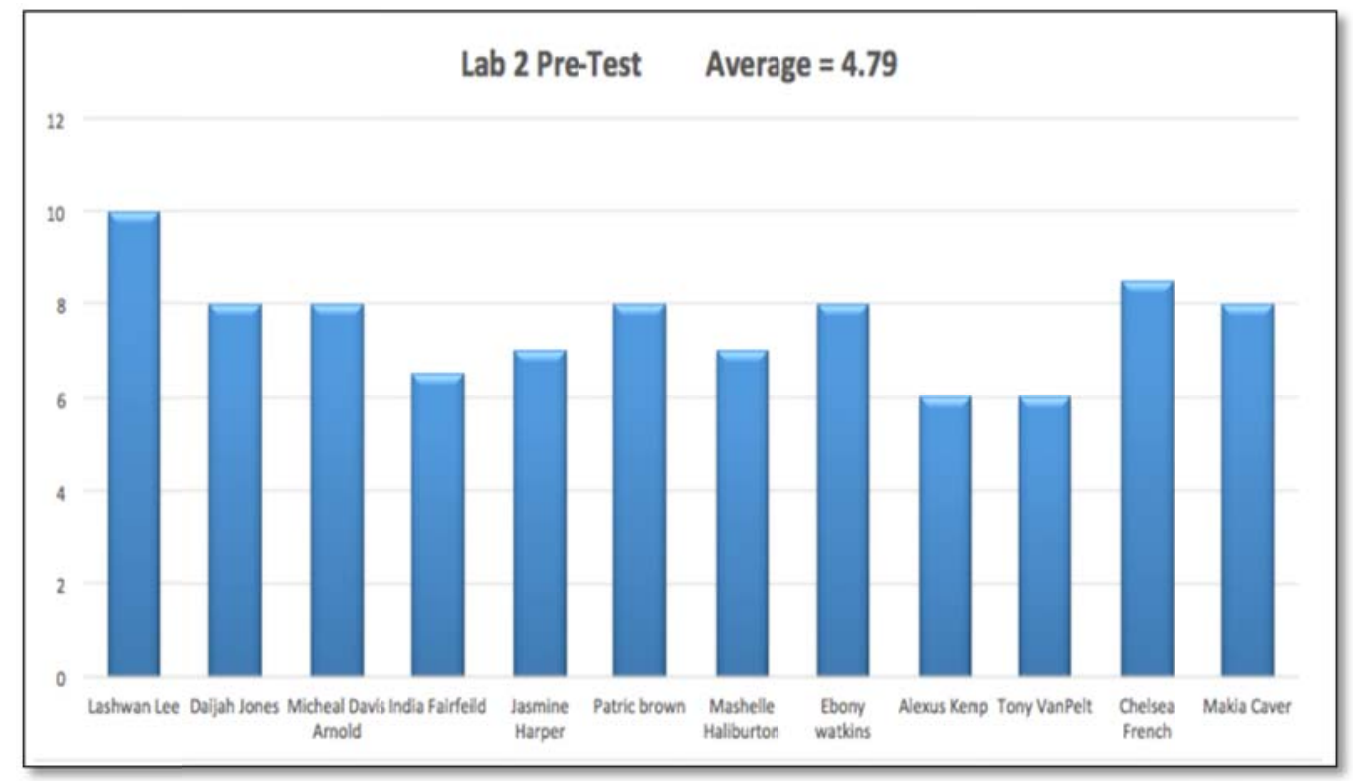

Figure 11: Results of Lab 2 , Pre-test

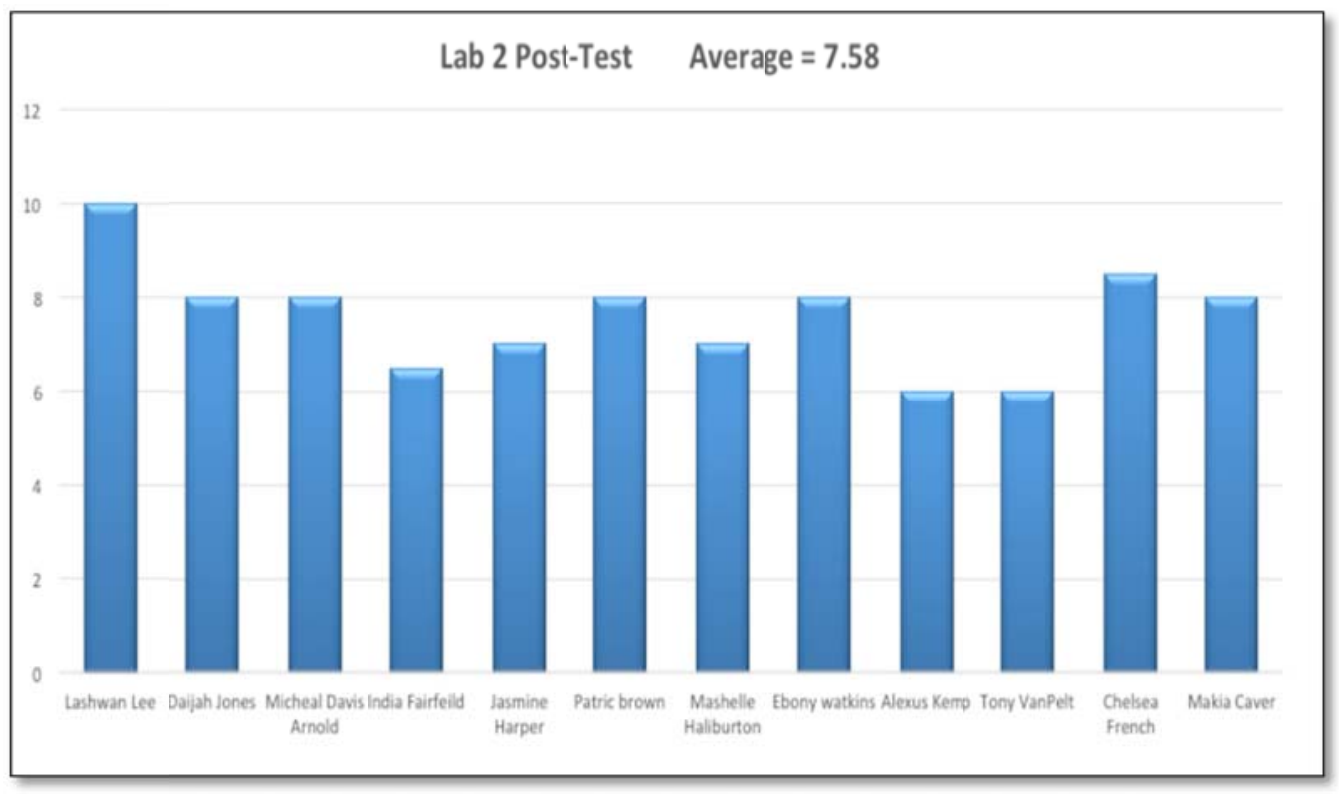

Figure 12: Results of Lab 2, Post test

For lab\#2, the analysis of this pre-test results (Fig. 11) revealed that, on an average, $47 \%$ of the answers to the ten questions were correct. In contrast, the Post test results (Fig. 12) showed that on average, students answered $75 \%$ of the questions correctly. 


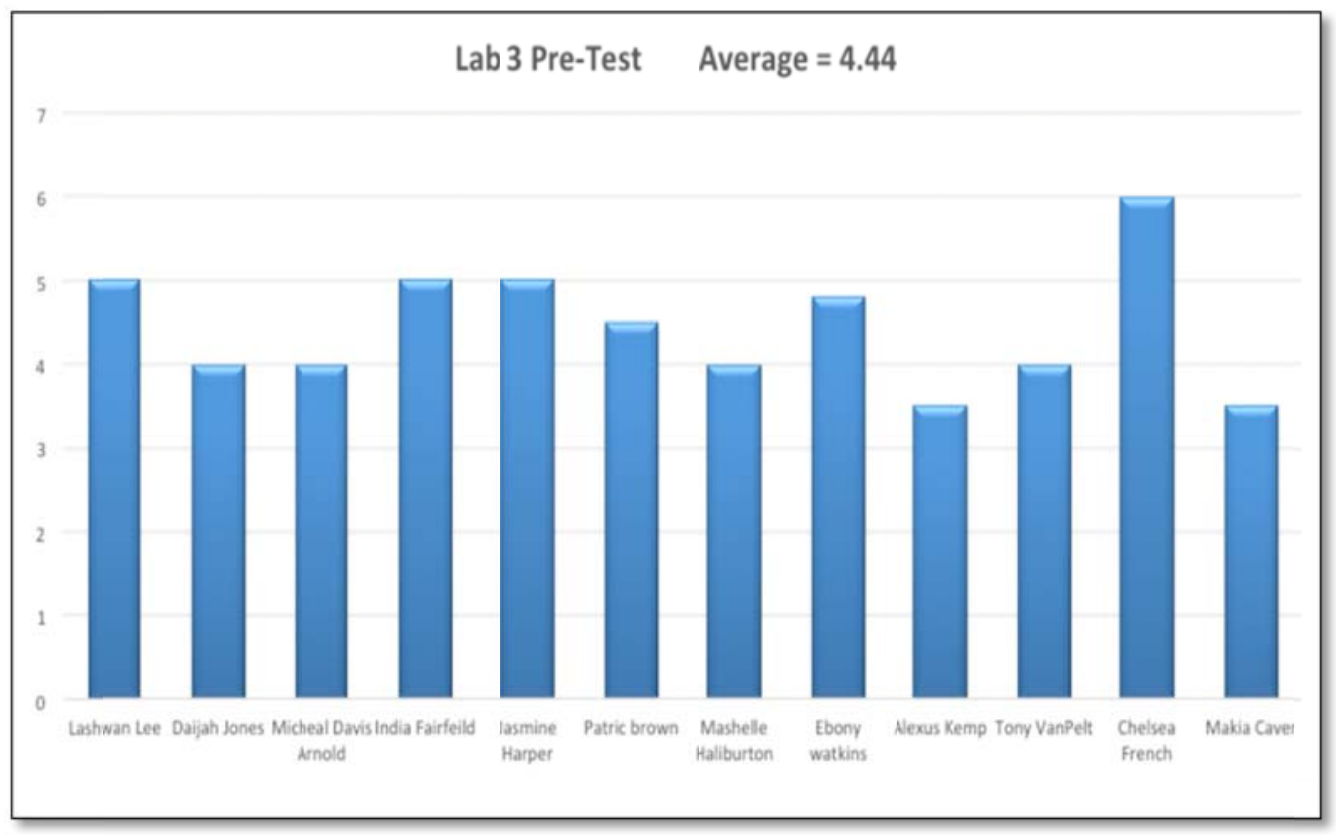

Figure 13: Results of Lab 3, Pre test

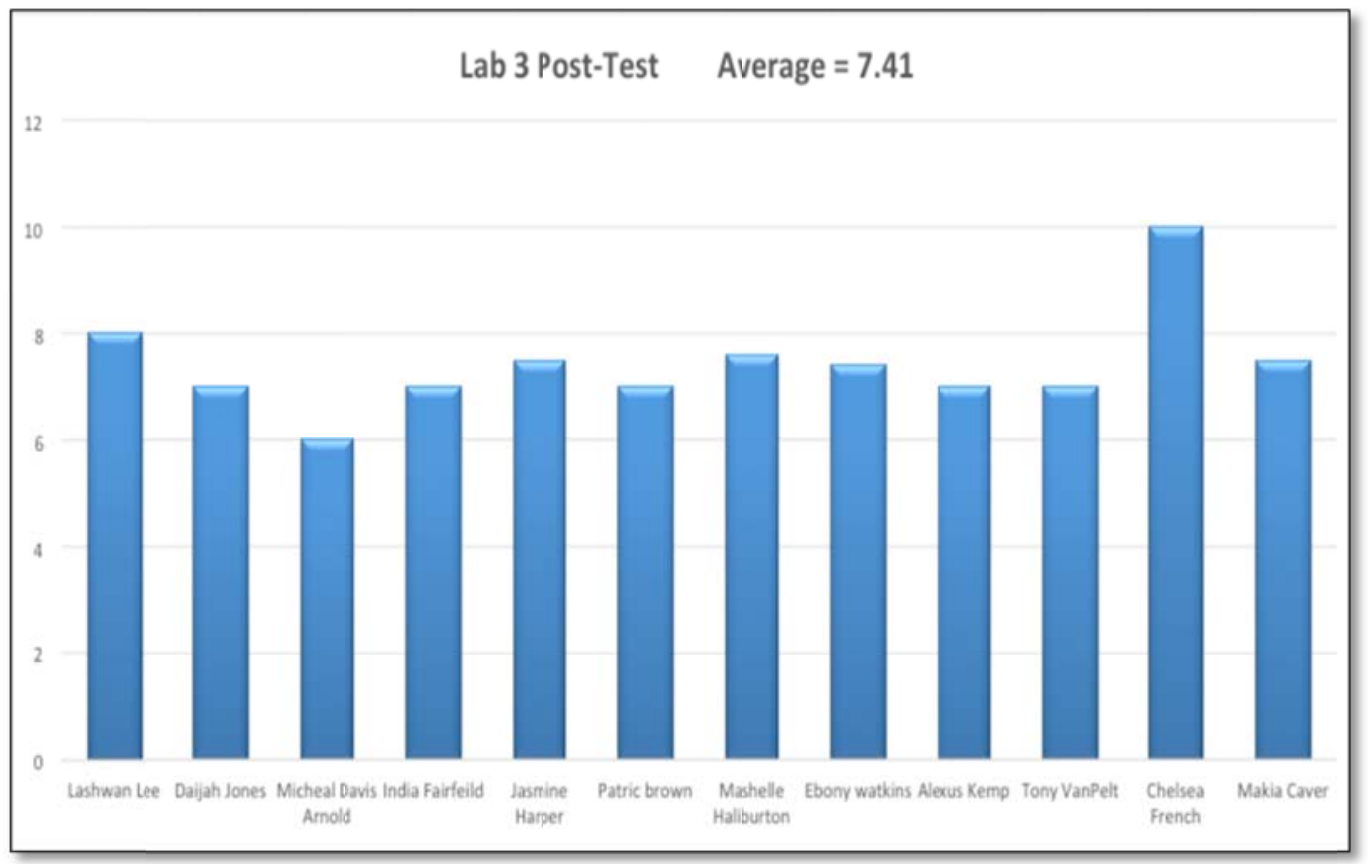

Figure 14 : Results of LAB 3 , Post test

For experiment\#3, the analysis of the pre-test results (Fig. 13) revealed that, on average, $44 \%$ of the answers to the ten questions were correct. However, the Post-test results (Fig. 14) showed that, on average, students answered $74 \%$ of questions correctly. 


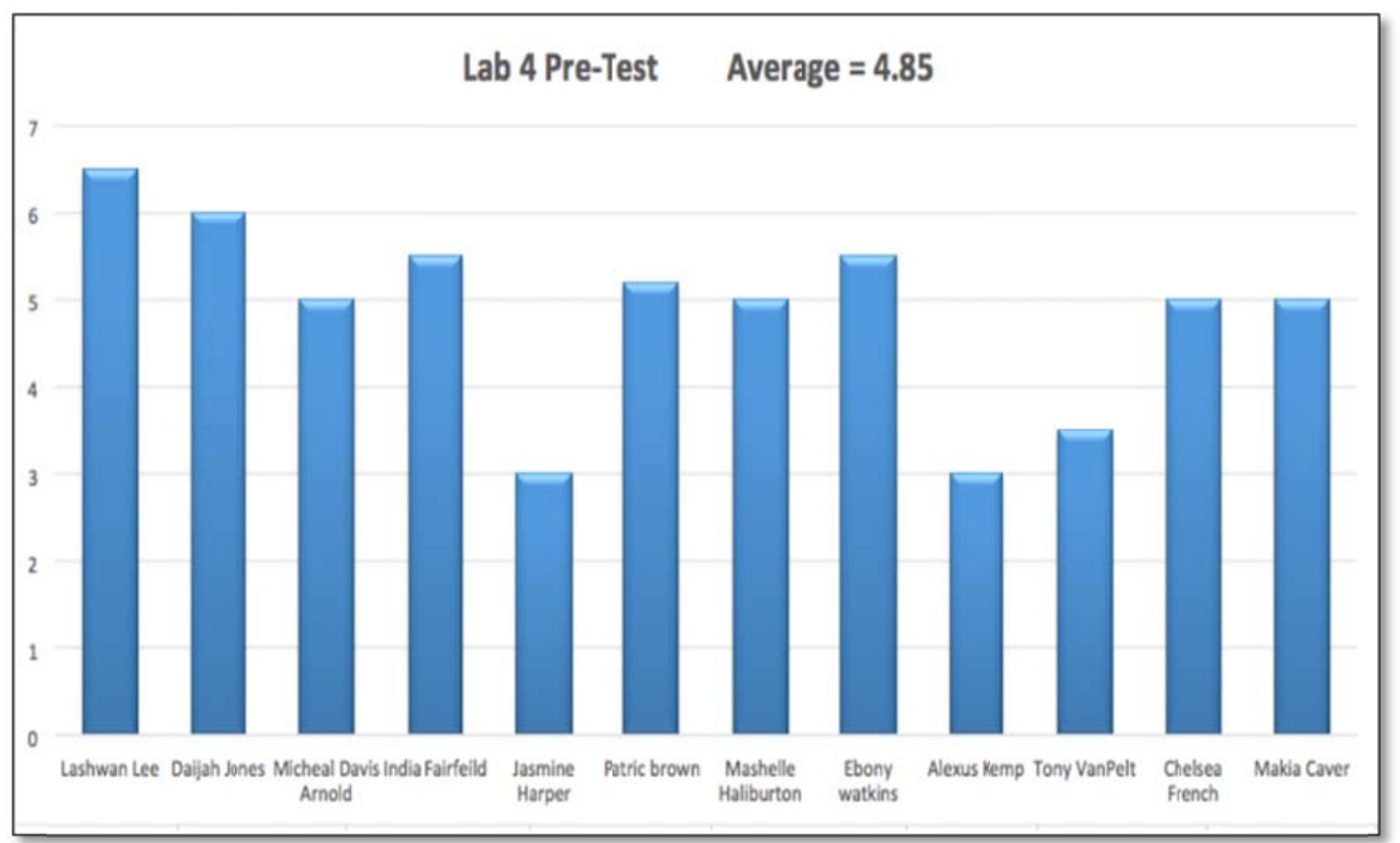

Figure 15 : Results of Lab 4. Pre-test

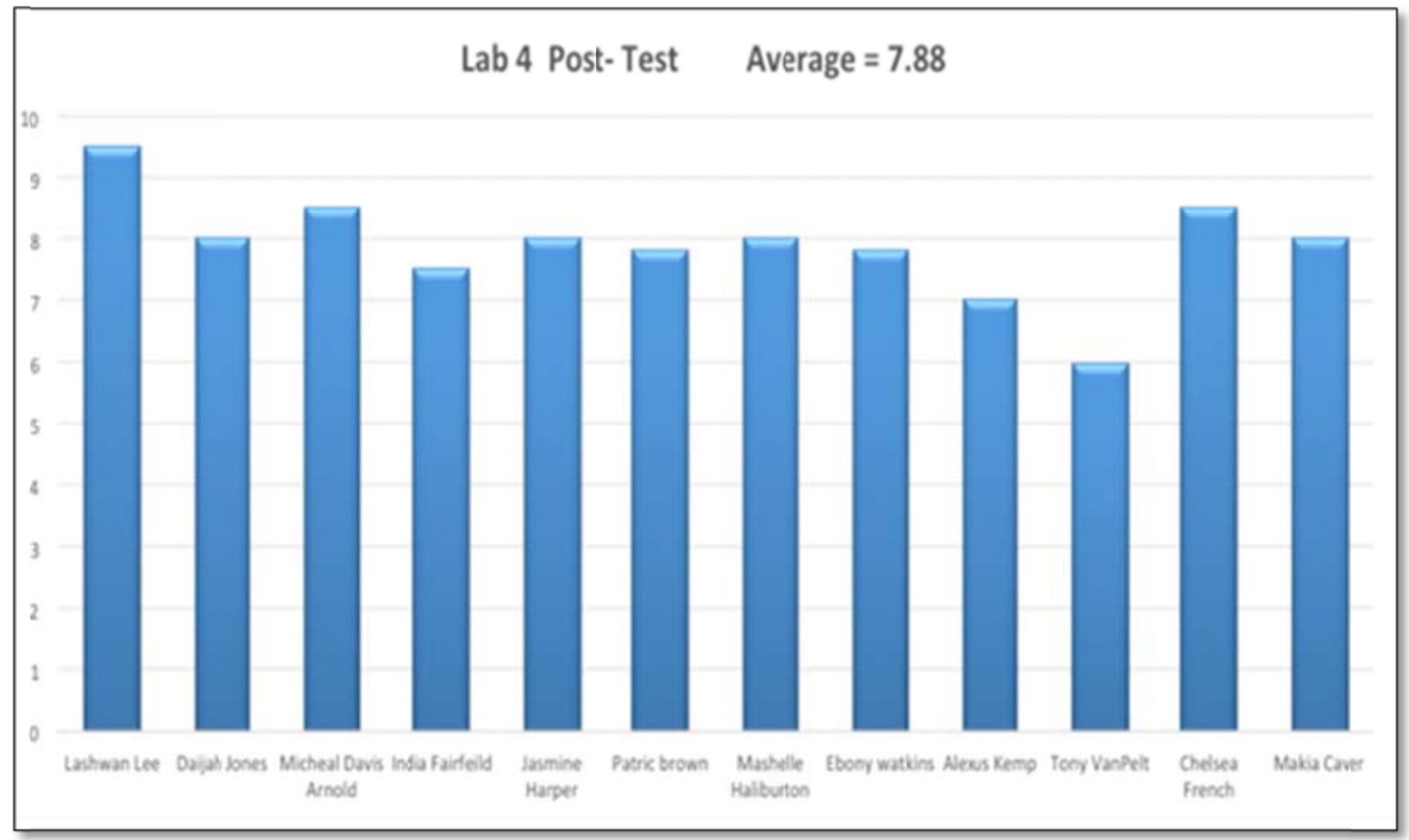

F

igure 6 : Results of Lab 4 , post test

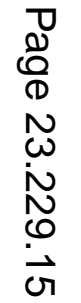


For the last lab, the analysis of the pre-test results (Fig. 15), revealed that, on average, $48 \%$ of the answers to the ten questions were correct. In contrast, the Post test results (Fig. 16) showed that, on average, students, answered $78 \%$ of questions correctly.

Students were satisfied with this new way of teaching. In fact, their feedback shows $82 \%$ satisfaction. It should be noted that, a more detailed assessment study of the learning effectiveness of virtual physics lab is planned in spring 2013 semester. If this also shows positive results, then further extensions of the virtual physics lab will be planned in the future.

\section{Conclusion}

This paper examined the potential of a game based virtual laboratory environment (both gamelike navigation and game-based experiments) as an educational tool. Virtual physics lab was introduced to the students for college physics preparation. The high school students needed quality education at a fraction of the cost of a traditional classroom lecture, which they received. Quality education in physics requires both lecture and lab practice, which was made possible for the first time in the Upward bound program through the use of a realistic and interactive virtual lab that is motivating because of the game like navigation as well as the game-based experiments. It was found that students consistently improved their knowledge of the concepts which were covered in the class. Also, they expressed their happiness about the virtual environment through a survey. The tool incorporates a high level 2D and 3D Simulations with video game like navigation in the virtual environment which helped keep the students engaged in the learning process, and resulted in better understanding of the subject as indicated by the consistent higher performance in the post-tests. 


\section{References}

1. Barone, C.A. (2003). Technology and the changing teaching and learning landscape:

Meetingthe needs of today's internet defined students. Website

http://www.aahea.org/bulletins/articles/educause.htm, accessed on 03/11/11.

2. Oblinger, D.G. \& Oblinger, J.L.(2006). Educating the Net generation. EDUCAUSE E- Book, Http://educause.edu/educatingthenetgen, accused on 03/11/11.

3. Oblinger, D.G.(2006) learning spaces. EDUCAUSE E-Book, Http://www.educause.edu/Leaningspaces, accessed on 03/11/11.

4. Kearney, p. (2007). Cognitive assessment of game-based learning. British Journal of education Technology, Vol . 38, No3, pp.529-531.

5. Twigg, C.A. Innovation in online Learning: Moving beyond No Significant Difference. The Pew Learning and Technology Program, 2001.

6. Allen, E., and Seaman, J. Going the distance: online education in the United States 2011. The sloan Consortium, November 2011. See also URL http;//sloanconsortium.org

7. Wasfy, h.m., Wasfy, T.M., Peters, J.M and Mahfouz, R.M, "Virtual Reality Enhanced Online Learning environments as a Substitute for Classroom Instruction. “ASME DETC2011-48826, Proceedings of the ASME 2011 International design Engineering Technical Conferences \& Computers and information in Engineering Conference (IDET/CIE), Washington D.C., August 2011.

8. Trends in collage pricing 2011. The College Board, 2011. See also URL http://www.collageboard.org

9. Fernandez, E., Workman-german, J., El-Mounayri , H., and Padalia, C.”Assessment of the Pedagogical Value of an Innovatiive E-Learning Envirorment That Uses Reality", 2008 ASEEIL/IN conference st Rpse Hulman Institute of technology , April 3-5, 2008 .

10. Wasfy, T.M., Wasfy, A.M., El-Mounayri, H., and Aw, D., “ virtual training environment for a 3 -axis CNC milling machine, ,DETC2005-84689, 25TH computers and Information in engineering conference, Wsington, DC, August 2011.

11. Information regarding upward bound program in the federal government website , in http://www2.ed.gov/programs/trioupbound/index.html 


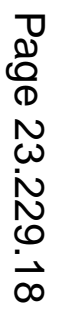

